\title{
Kinetics of the Volatilization Removal of Zinc from Manganese Dust
}

\author{
Byung-Su Kim ${ }^{1, *}$, Jae-chun Lee ${ }^{1}$, Soo-Bock Jeong ${ }^{1}$, Hoo-in Lee ${ }^{1}$ and Chan Wook Kim ${ }^{2}$ \\ ${ }^{1}$ Minerals \& Materials Processing Division, Korea Institute of Geoscience \& Mineral Resources (KIGAM), Daejeon, Korea \\ ${ }^{2}$ Reserach Institute of Industrial Science \& Technology (RIST), Pohang, Gyeongbuk, Korea
}

\begin{abstract}
Manganese dust which contains significant amounts of manganese, zinc and potassium is collected from the off-gas during manufacturing ferromanganese and silicomanganese alloys at Dongbu Metal Company in Korea. The removal of zinc and potassium from the manganese dust is very important in the process for recycling the dust back into the ferromanganese smelting furnace. This is because the potential accumulation of zinc and potassium in the smelting furnace can cause irregularities in the operation of the smelting furnace. In this study, the reductionvolatilization reaction of the zinc oxide contained in the manganese dust with carbon was examined at reaction temperatures between 923 and $1323 \mathrm{~K}$ in nitrogen atmosphere using a thermogravimetric method. The results of experiments on the kinetics of the reaction are presented in this paper. Experimentally, the rate of this reaction was demonstrated by the removal of $99 \%$ zinc in 20 min at $1198 \mathrm{~K}$ under a carbon addition amount of 9 mass $\%$. The reduction-volatilization reaction started at above $973 \mathrm{~K}$ and proceeded very fast at above $1023 \mathrm{~K}$. Furthermore, manganese and iron oxides in the dust was partially reduced during the reaction. The shrinking-core model for a surface chemical reaction control was found to be useful in describing the reduction-volatilization reaction rate, which had an activation energy of $173 \mathrm{~kJ} / \mathrm{mol}(41.3$ $\mathrm{kcal} / \mathrm{mol}$ ). [doi:10.2320/matertrans.M2010108]
\end{abstract}

(Received March 23, 2010; Accepted April 19, 2010; Published June 25, 2010)

Keywords: manganese dust, recycling, reduction-volatilization, shrinking-core model

\section{Introduction}

In a typical semi-sealed electric arc furnace operation for manufacturing ferromanganese and silicomanganese alloys, significant amounts of the charge are converted into dust. Currently, over 10,000 tons of manganese dust are produced each year at Dongbu Metal Company (Dongbu) in Korea which produces 250,000 tons per year of ferromanganese and silicomanganese alloys in semi-sealed electric arc furnaces. ${ }^{1)}$ The manganese dust is collected from the furnace off-gas dry scrubbers. The manganese dust, which can be considered as a byproduct of the manganese alloy smelting processes, contains over 25 mass\% manganese that can be recovered. Since the natural manganese oxide concentrates are becoming low grade and the use of manganese continues to increase in the steel industry, the amount of the dust generated in the manganese alloy smelting processes will rise concurrently. In addition, the dust is classified as a hazardous waste in Korea because of its unacceptable levels of leachable toxic metals such as zinc and lead and so on. Dongbu is thus developing a technology to utilize the manganese dust as a manganese resource with reducing an environmental liability.

Recycling of manganese dust back into the ferromanganese smelting furnace would not only reduce an environmental liability caused by its dump-site but also decrease manganese ore consumption by recovering manganese contained in the dust. However, the manganese dust generated from Dongbu contains 3 10 mass $\%$ zinc and 15 20 mass\% potassium which have to be removed prior to feeding the dust into the ferromanganese smelting furnace. This is due to the potential accumulation of zinc and potassium in the low temperature region of the smelting furnace, which can cause detrimental effects in the smelting operation. So far, a few researches on the recycling of manganese dust back into the ferromanganese smelting furnace were reported in literature. ${ }^{2,3)}$ In spite of that,

*Corresponding author, E-mail: bskim@kigam.re.kr very little fundamental kinetic on the removal behavior of detrimental components such as zinc and potassium are available, which is a major concern for an optimal design of the recycling process of manganese dust. Further information was thus required on the removal behavior of detrimental components such as zinc and potassium.

Dongbu is developing a recycling technology to utilize the manganese dust as a manganese resource, which contains the removal of potassium by a water washing process, followed by a reduction-volatilization reaction process of zinc oxide by carbon. In the present study, the rate of the reduction-volatilization reaction of zinc oxide remained in the manganese dust after the water washing process was investigated using a thermogravimetric method. The rate data reported in this paper was determined by eliminating the effects of external mass transfer.

\section{Thermodynamic Considerations}

The reduction equilibrium phase diagram of the important phases involved in the reduction-volatilization reaction of zinc oxide in the manganese dust with carbon is presented in Fig. 1. Figure 1 is the reduction equilibrium phase diagram of $\mathrm{Mn}-\mathrm{Zn}-\mathrm{Fe}-\mathrm{CO}(\mathrm{g})-\mathrm{CO}_{2}(\mathrm{~g})$ system. Here, the activities of all condensed phases were assumed to be one, the thermodynamic data obtained from HSC Chemistry 5.1 (A. Roine, Outokumpu, 2002) version. This figure reveals that in case the sum of the partial pressure of $\mathrm{CO}_{2}(\mathrm{~g})$ and $\mathrm{CO}(\mathrm{g})$ is $0.21 \mathrm{~atm}$, the stable phases are $\mathrm{Fe}, \mathrm{ZnO}$ and $\mathrm{MnO}$ under $1180 \mathrm{~K}$ and $\mathrm{Fe}, \mathrm{Zn}(\mathrm{g})$ and $\mathrm{MnO}$ over $1180 \mathrm{~K}$. It is also shown in the figure that the equilibrium vapor pressure of zinc increases with increasing in the reaction temperature, and the removal of zinc in manganese dust is possible under the partial reduction condition of manganese and iron oxides. In addition, the equilibrium zinc vapor pressure was investigated to increase with increasing in the ratio of the partial pressures of $\mathrm{CO}(\mathrm{g})$ and $\mathrm{CO}_{2}(\mathrm{~g})$, as represented in the zinc vapor pressure lines of Fig. 1. 


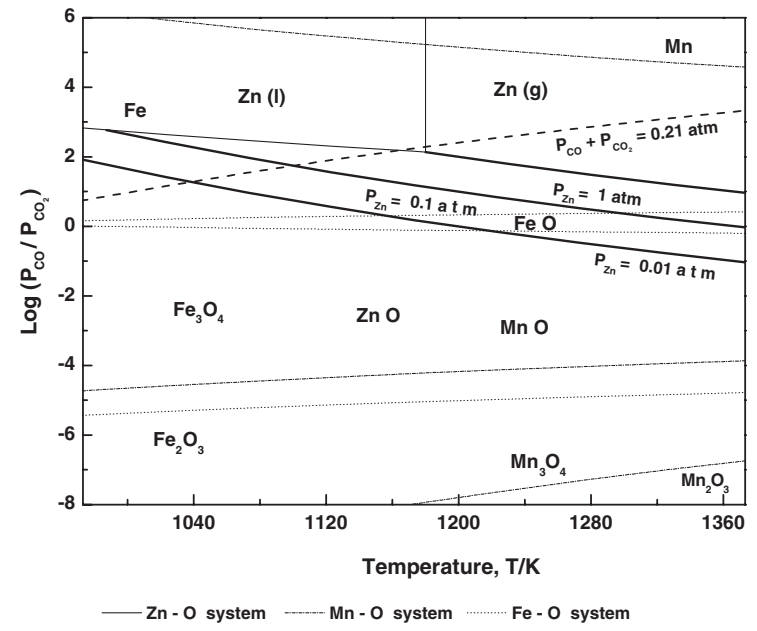

Fig. 1 Reduction equilibrium phase diagram for $\mathrm{Mn}-\mathrm{Zn}-\mathrm{Fe}-\mathrm{CO}(\mathrm{g})-\mathrm{CO}_{2}(\mathrm{~g})$ system.

Table 1 The important reactions and the Gibbs energy changes involved in the reduction-volatilization reaction of zinc oxide in the manganese dust with carbon.

\begin{tabular}{ccrr}
\hline \multirow{2}{*}{ Reaction No. } & Reaction & \multicolumn{2}{c}{$\Delta G^{\mathrm{o}}(\mathrm{kJ} / \mathrm{mol})$} \\
\cline { 3 - 4 } & $\mathrm{ZnO}+\mathrm{C} \rightarrow \mathrm{Zn}(\mathrm{g})+\mathrm{CO}(\mathrm{g})$ & 87.86 & -29.64 \\
\hline 1 & $\mathrm{ZnO}+\mathrm{CO}(\mathrm{g}) \rightarrow \mathrm{Zn}(\mathrm{g})+\mathrm{CO}_{2}(\mathrm{~g})$ & 79.06 & 31.23 \\
\hline 3 & $\mathrm{CO}_{2}(\mathrm{~g})+\mathrm{C} \rightarrow 2 \mathrm{CO}(\mathrm{g})$ & 8.80 & -60.87 \\
\hline 4 & $\mathrm{Mn}_{2} \mathrm{O}_{3}+\mathrm{C} \rightarrow 2 \mathrm{MnO}+\mathrm{CO}(\mathrm{g})$ & -109.40 & -186.82 \\
\hline 5 & $\mathrm{Mn}_{2} \mathrm{O}_{3}+\mathrm{CO}(\mathrm{g}) \rightarrow 2 \mathrm{MnO}+\mathrm{CO}_{2}(\mathrm{~g})$ & -118.21 & -125.95 \\
\hline 6 & $\mathrm{Mn}_{3} \mathrm{O}_{4}+\mathrm{C} \rightarrow 3 \mathrm{MnO}+\mathrm{CO}(\mathrm{g})$ & -77.56 & -160.92 \\
\hline 7 & $\mathrm{Mn}_{3} \mathrm{O}_{4}+\mathrm{CO}(\mathrm{g}) \rightarrow 3 \mathrm{MnO}+\mathrm{CO}_{2}(\mathrm{~g})$ & -86.36 & -100.05 \\
\hline 8 & $\mathrm{Fe}_{2} \mathrm{O}_{3}+\mathrm{C} \rightarrow 2 \mathrm{FeO}+\mathrm{CO}(\mathrm{g})$ & -23.31 & -104.80 \\
\hline 9 & $\mathrm{Fe}_{2} \mathrm{O}_{3}+\mathrm{CO}(\mathrm{g}) \rightarrow 2 \mathrm{FeO}+\mathrm{CO}_{2}(\mathrm{~g})$ & -32.11 & -43.92 \\
\hline 10 & $\mathrm{Fe}_{3} \mathrm{O}_{4}+\mathrm{C} \rightarrow 3 \mathrm{FeO}+\mathrm{CO}(\mathrm{g})$ & 9.63 & -65.40 \\
\hline 11 & $\mathrm{Fe}_{3} \mathrm{O}_{4}+\mathrm{CO}(\mathrm{g}) \rightarrow 3 \mathrm{FeO}+\mathrm{CO}_{2}(\mathrm{~g})$ & 0.83 & -4.52 \\
\hline 12 & $\mathrm{Fe}_{2} \mathrm{O}_{3}+3 \mathrm{C} \rightarrow 2 \mathrm{Fe}+3 \mathrm{CO}(\mathrm{g})$ & -2.07 & -206.62 \\
\hline 13 & $\mathrm{Fe}_{2} \mathrm{O}_{3}+3 \mathrm{CO}(\mathrm{g}) \rightarrow 2 \mathrm{Fe}+3 \mathrm{CO}_{2}(\mathrm{~g})$ & -28.47 & -24.00 \\
\hline 14 & $\mathrm{Fe}_{3} \mathrm{O}_{4}+4 \mathrm{C} \rightarrow 3 \mathrm{Fe}+4 \mathrm{CO}_{(\mathrm{g})}$ & 41.50 & -218.12 \\
\hline 15 & $\mathrm{FeO}_{2}+\mathrm{C} \rightarrow \mathrm{Fe}+\mathrm{CO}(\mathrm{g})$ & 10.62 & -50.91 \\
\hline & & &
\end{tabular}

Based on the reduction equilibrium phase diagram of $\mathrm{Mn}-\mathrm{Zn}-\mathrm{Fe}-\mathrm{CO}(\mathrm{g})-\mathrm{CO}_{2}(\mathrm{~g})$ system, the important reactions and the Gibbs energy changes involved in the reductionvolatilization reaction of zinc oxide in manganese dust with carbon are described in Table 1. The reactions (3) to (15) might be thermodynamically more favorable than the reactions (1) and (2) under the considered temperature range between $923 \mathrm{~K}$ and $1323 \mathrm{~K}$, as shown in the table. Also, the reduction-volatilization reaction of zinc oxide with carbon is well known to be the reaction (1) which is a combination of the reactions (2) and (3). ${ }^{4)}$ Therefore, it was considered in the study that enough amount of carbon as a reducing agent to reduce zinc oxide as well as manganese and iron oxides contained in manganese dust must be necessary for the removal of zinc in the dust.
Table 2 Elemental composition of Dongbu's manganese dust.

\begin{tabular}{ccc}
\hline \multirow{2}{*}{ Element } & \multicolumn{2}{c}{ Concentration (mass\%) } \\
\cline { 2 - 3 } & Before washing & *After washing \\
\hline $\mathrm{Mn}$ & 27.50 & 37.80 \\
\hline $\mathrm{Zn}$ & 3.16 & 4.38 \\
\hline $\mathrm{C}$ & 4.78 & 4.13 \\
\hline $\mathrm{S}$ & 1.51 & 0.19 \\
\hline $\mathrm{Fe}$ & 1.04 & 1.42 \\
\hline $\mathrm{K}$ & 17.50 & 2.38 \\
\hline $\mathrm{Na}$ & 1.29 & 0.51 \\
\hline
\end{tabular}

${ }^{*}$ Dried at $378 \mathrm{~K}$ for 1 day after washing.

\section{Experimental}

Experiments were carried out in a thermogravimetic analysis (TGA) apparatus, described in detail elsewhere. ${ }^{5)}$ In the experiment, a weighed amount of manganese dust and carbon was first mixed thoroughly and placed in an alumina plate, and then the sample plate was introduced in a shallow silica tray which is suspended by a platinum chain into a reactor tube located within vertical tubular furnace. A sample weight of $350 \mathrm{mg}( \pm 25 \mathrm{mg})$ of the solid reactants was used for each run. During heating, a steady flow of $11.7 \mathrm{~mL} / \mathrm{s}$ of dry nitrogen was maintained through the reactor tube, the microbalance protected from hot gases by flushing it with a dry nitrogen gas of $25.0 \mathrm{~mL} / \mathrm{s}$. After a stipulated time period, the reaction was stopped by sliding down the furnace, the sample tray cooled down in air.

Dongbu's manganese dust used in this study was obtained from the furnace off-gas dry scrubbers during the semi-sealed electric arc furnace operation for manufacturing ferromanganese and silicomanganese alloys. The particles ranged $\sim 4 \mu \mathrm{m}$ in size. The manganese dust obtained was first washed by water $(20 \mathrm{~g} / \mathrm{L}$ of pulp density) for $60 \mathrm{~min}$ at $298 \mathrm{~K}$ to remove potassium in the dust. It was carried out to minimize the effect of that on the reduction-volatilization reaction of zinc oxide in the dust with carbon. The humidity contained in the washed dust was removed by drying for $24 \mathrm{~h}$ at $378 \mathrm{~K}$. The elemental compositions of the dust before and after the washing are shown in Table 2. The major elements in the dust before the washing are 27.5 mass $\%$ manganese, 3.16 mass $\%$ zinc, 4.78 mass $\%$ carbon and 17.5 mass $\%$ potassium, while those after the washing are 37.8 mass $\%$ manganese, 4.38 mass \% zinc, 4.13 mass $\%$ carbon and 2.38 mass $\%$ potassium. In the washing, negligible amounts of manganese and zinc were leached out. In the study, the washed manganese dust was used to measure the kinetics on the reduction-volatilization reaction of the zinc oxide with carbon. Also, analytical grade carbon $(\sim 74 \mu \mathrm{m}$ of particle size) manufactured by Junsei Chemical Company in Japan was used as a reducing agent to reduce zinc oxide in the dust. $\mathrm{X}$-ray diffraction patterns of the washed dust are shown in Fig. 2. This figure shows that the major identified peaks in the pattern are $\mathrm{MnO}$ and $\mathrm{Mn}_{3} \mathrm{O}_{4}$. However, no zinc, potassium and iron containing phases were detected by $\mathrm{X}$-ray diffraction patterns due to their low contents, as shown in Table 2. 


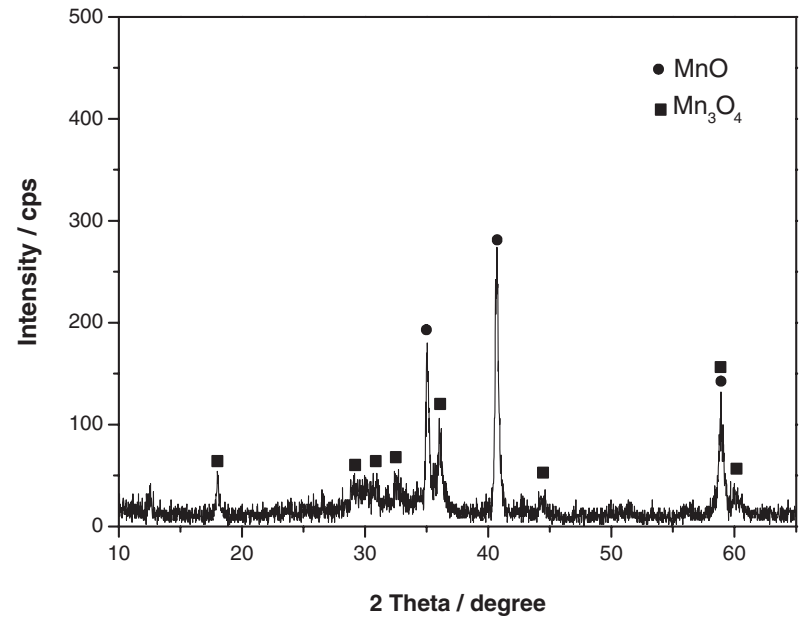

Fig. 2 X-ray diffraction patterns of the washed manganese dust.

The morphological characterization of the samples was performed using a scanning electron microscope (JSM6380LV, JEOL Ltd, Tokyo, Japan) equipped with an energy dispersive X-ray spectrometer (Link Isis 3.0, Oxford Instrument plc, Oxon, U.K). The X-ray diffraction patterns were obtained using a X-ray diffractometer (Rigaku D-max2500PC, Rigaku/MSC, Inc., TX, U.S.A) with $\mathrm{Cu} \mathrm{K} \alpha$ radiation $(\lambda=0.154 \mathrm{~nm})$ operated at $40 \mathrm{kV}$ and $30 \mathrm{~mA}$. Samples before and after the reduction-volatilization reaction were also analyzed for Fe by wet chemistry and for Mn, Zn, $\mathrm{K}$ and $\mathrm{Na}$ by the inductively coupled plasma (ICP) method (JY-38 plus, Horiba Ltd, Kyoto, Japan). The carbon and the sulfur contents were determined by the LECO method.

\section{Experimental Results and Discussion}

\subsection{Effect of carbon addition amount}

The washed manganese dust used in the study contains more carbon $(4.13$ mass $\%)$ than is needed for the reduction of zinc oxide in the dust. The amount of carbon needed for the reduction-volatilization removal of zinc oxide in the dust was calculated to be about 0.8 mass $\%$ based on the zinc content in Table 2. Although that, it was also reported that most of carbon contained in the dust is tar components which is easily decomposed and vaporized. ${ }^{2,3)}$ Thus, the effect of the carbon addition amount on the removal of zinc from the dust was investigated with varying the amount of carbon $(0 \sim 15$ mass $\%)$ under a reaction time of $20 \mathrm{~min}$ and a reaction temperature of $1223 \mathrm{~K}$. The results presented in Fig. 3 show that without addition of carbon, the zinc was found not to be nearly removed. This might be the reason why most of carbon contained in the dust is tar components, as reported by the previous researchers. ${ }^{2,3)}$ However, the zinc removal percentage was found to increase with increasing in the carbon addition amount. This is the reason that increasing the carbon addition results in an increase in the reaction surface area and provides more carbon monoxide. Also, the result shows that more carbon than is needed for the reduction-volatilization removal of zinc oxide in the dust is necessary for removing zinc in the dust. This is probably the reason that during the reduction-volatilization reaction, manganese and iron oxides in the dust is partially reduced, as

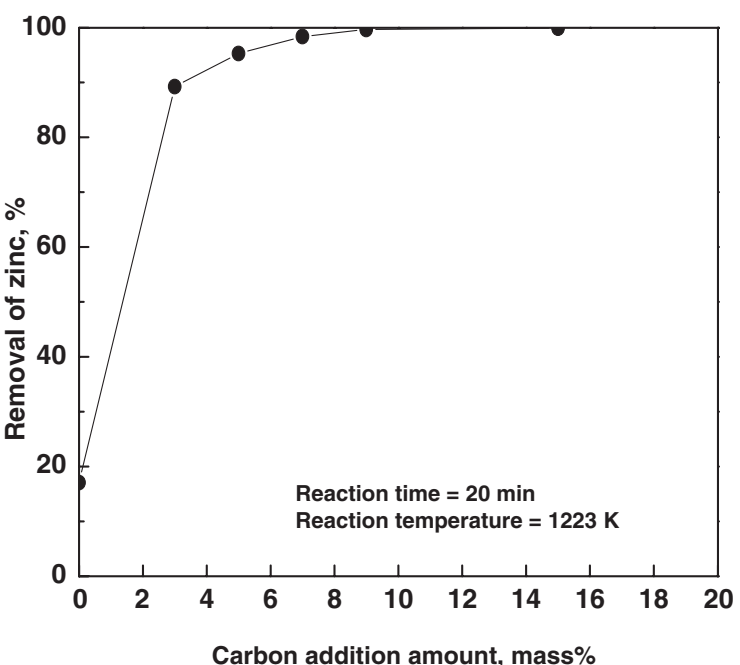

Fig. 3 Effect of carbon addition amount on the removal of zinc from the manganese dust.

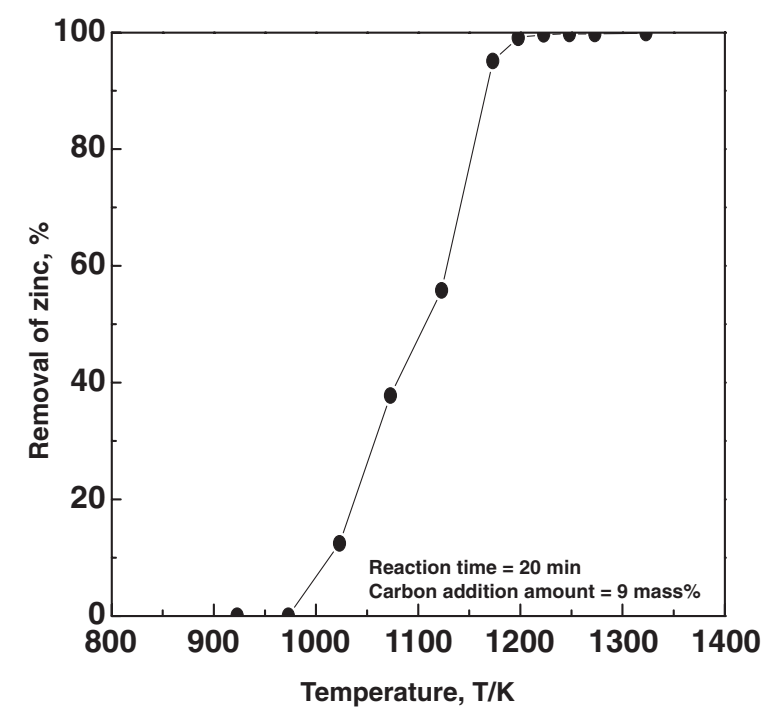

Fig. 4 Effect of reaction temperature on the removal of zinc from the manganese dust.

expected in the thermodynamic consideration. As shown in Fig. 3, about $90 \% \sim 95 \%$ of the zinc in the dust was removed at the carbon addition amount range between $3 \%$ and $5 \%$ which is similar to the stoichiometric amount of carbon required to reduce zinc, manganese and iron oxides in the dust, and the zinc in the dust was almost completely removed at the carbon addition amounts over 9 mass\%. Thus, in all of the subsequent experiments, a working carbon addition amount of 9 mass $\%$ was fixed to measure the rate on the reduction-volatilization reaction of zinc oxide in the dust with carbon with minimizing the external diffusion effect in the apparatus.

\subsection{Effect of reaction temperature}

To examine the effect of reaction temperature, the studies were carried out at several temperatures for $20 \mathrm{~min}$ and the results are presented in Fig. 4. The removal of zinc was found to be nearly negligible below $973 \mathrm{~K}$, but the increase in the removal percentage of zinc with increasing the reaction 


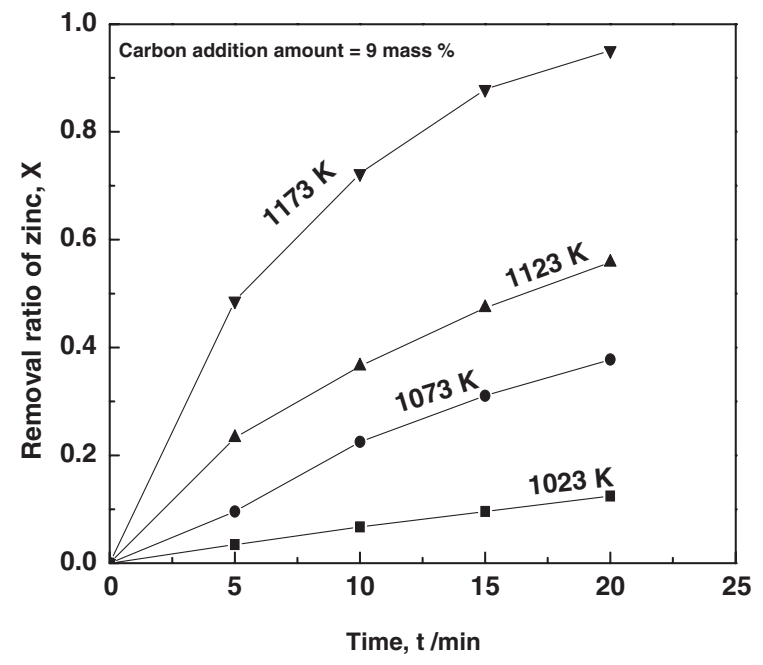

Fig. 5 Effect of reaction time on the removal of zinc from the manganese dust.

temperature was observed. The figure reveals that the reduction-volatilization reaction proceeds very fast at above $1023 \mathrm{~K}$. Also, increasing the temperature over $1198 \mathrm{~K}$ resulted in the zinc removal percentage over $99 \%$. That might be the reason why the temperature range is over the boiling temperature of zinc $(1180 \mathrm{~K})$ which a high vapor pressure of zinc is formed.

\subsection{Effect of reaction time}

To examine the rate of the reduction-volatilization reaction of zinc oxide in the dust with carbon, the experiments was carried out with varying the reaction time until $20 \mathrm{~min}$ at reaction temperatures between 1023 and $1173 \mathrm{~K}$ under nitrogen atmosphere, while all other experimental variables, such as sample weight and gas flow rate, were nearly identical for the measurement. The results are presented in Fig. 5. Here, the rates were measured by minimizing the effects of external mass transfer by using a sufficiently high flow rate $(11.7 \mathrm{~mL} / \mathrm{s})$ of nitrogen and small amount $350 \mathrm{mg}$ $( \pm 25 \mathrm{mg}$ ) of the solid sample, which was chosen through the preliminary experiments. The removal ratio at a particular time was determined by dividing the weight of zinc in the solid sample at the time by the initial zinc weight in the solid sample. It is seen in Fig. 4 that about $95 \%$ of zinc contained in the dust were removed in $20 \mathrm{~min}$ at $1173 \mathrm{~K}$ under a carbon addition amount of 9 mass\%. However, the removal of zinc was found to be about $12 \%$ in $20 \mathrm{~min}$ at $1023 \mathrm{~K}$.

\subsection{Interpretation of the rate data}

The reduction-volatilization reaction of zinc oxide with carbon is one of the gas-solid reactions in which no solid product is formed. In the study of the reaction of pure zinc oxide with carbon monoxide and carbon dioxide mixtures, Gonzalez et al. reported that the zinc oxide reacted with carbon monoxide without formation of solid product. ${ }^{6)}$ The rate was noticeably depended on carbon monoxide concentration and the reaction was chemically controlled. In the study of the reaction of pure zinc oxide with various additives, Kim et al. reported that a shrinking core model with chemical reaction control was found to fit the reaction

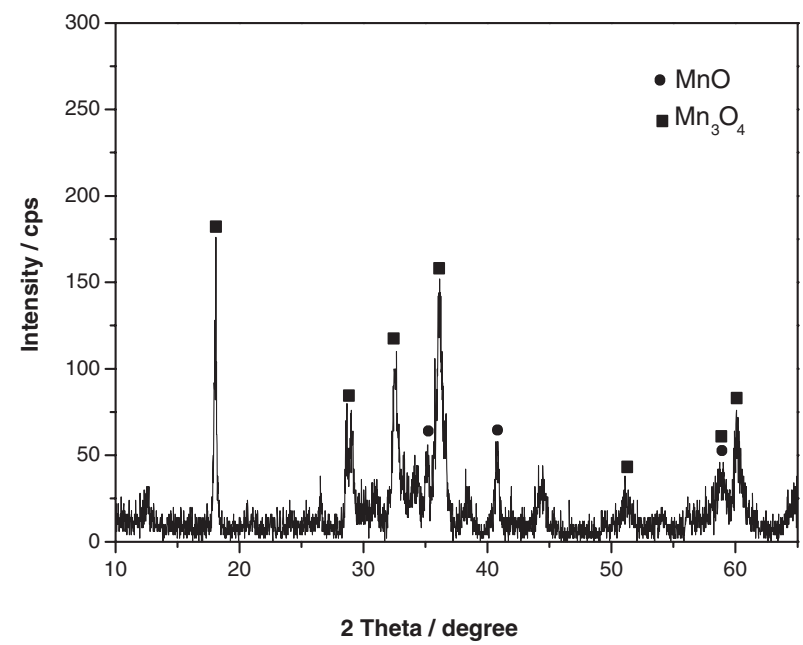

Fig. 6 X-ray diffraction patterns of the product solid sample obtained from the reduction-volatilization reaction of zinc oxide in the manganese dust with carbon for $20 \mathrm{~min}$ at $1173 \mathrm{~K}$.

rate, and the rate was promoted by the carbon gasification reaction. ${ }^{7)}$

In the reduction-volatilization reaction being studied, $\mathrm{X}$ ray diffraction patterns of the product solid sample obtained from the reaction for $20 \mathrm{~min}$ at $1173 \mathrm{~K}$ are presented in Fig. 6. It was found in Fig. 6 that the identified mineral for manganese in the product solid sample is $\mathrm{MnO}$ and $\mathrm{Mn}_{3} \mathrm{O}_{4}$. Here, the detection of $\mathrm{Mn}_{3} \mathrm{O}_{4}$ peaks might be due to the fast reoxidation reaction of $\mathrm{MnO}$ during the cooling step. ${ }^{8)}$ However, no zinc, potassium and iron containing phases were detected by X-ray diffraction patterns due to their low contents. In addition, the structure of solid sample produced by the reduction was observed by SEM-EDS. Figure 7 shows SEM-EDS results of the particles before and after the reaction. The micrograph shows that the manganese dust particles before the reaction are impervious as shown in Fig. 7(a), while after the reaction for $20 \mathrm{~min}$ at $1173 \mathrm{~K}$, the produced particles are quite porous as shown in Fig. 7(b). Also, zinc in the fresh particles before the reaction was detected by EDS analysis, while zinc in the produced particles after the reaction was slightly detected, as shown in the figure. Thus, the particle sizes of zinc oxide should decrease as the reduction-volatilization reaction proceeds. Based on these observations, spherical shrinking-core model with chemical reaction control is expected to best represent the reduction-volatilization reaction of zinc oxide in the dust with carbon. This was verified after trying a number of different rate equations, such as the nucleation and growth model and the power law. In the spherical shrinking-core model rate equation for a surface chemical reaction-controlled reaction, the removal ratio of zinc by the reductionvolatilization reaction of zinc oxide in the dust with carbon is related to the reaction time by ${ }^{9}$

$$
1-(1-X)^{1 / 3}=k_{\mathrm{r}} \cdot t
$$

Here, $X$ is the removal ratio of zinc in the dust, $t$ is the reaction time $(\mathrm{min})$, and $k_{\mathrm{r}}$ is a rate constant $\left(\mathrm{min}^{-1}\right)$ that is a function of temperature. It is apparent from eq. (1) that a plot of $1-(1-X)^{1 / 3}$ versus $t$ should be linear with $k_{\mathrm{r}}$ as the slope. 

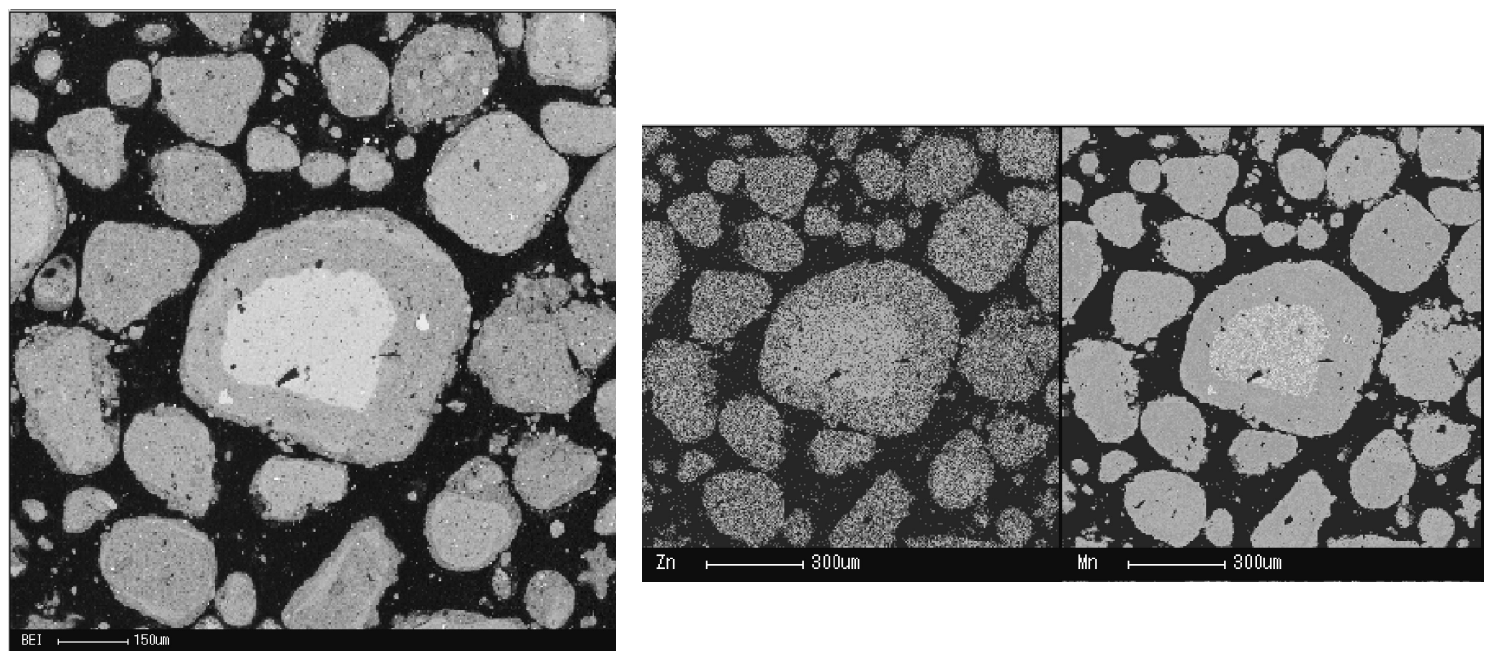

(a) The fresh particles before reacting
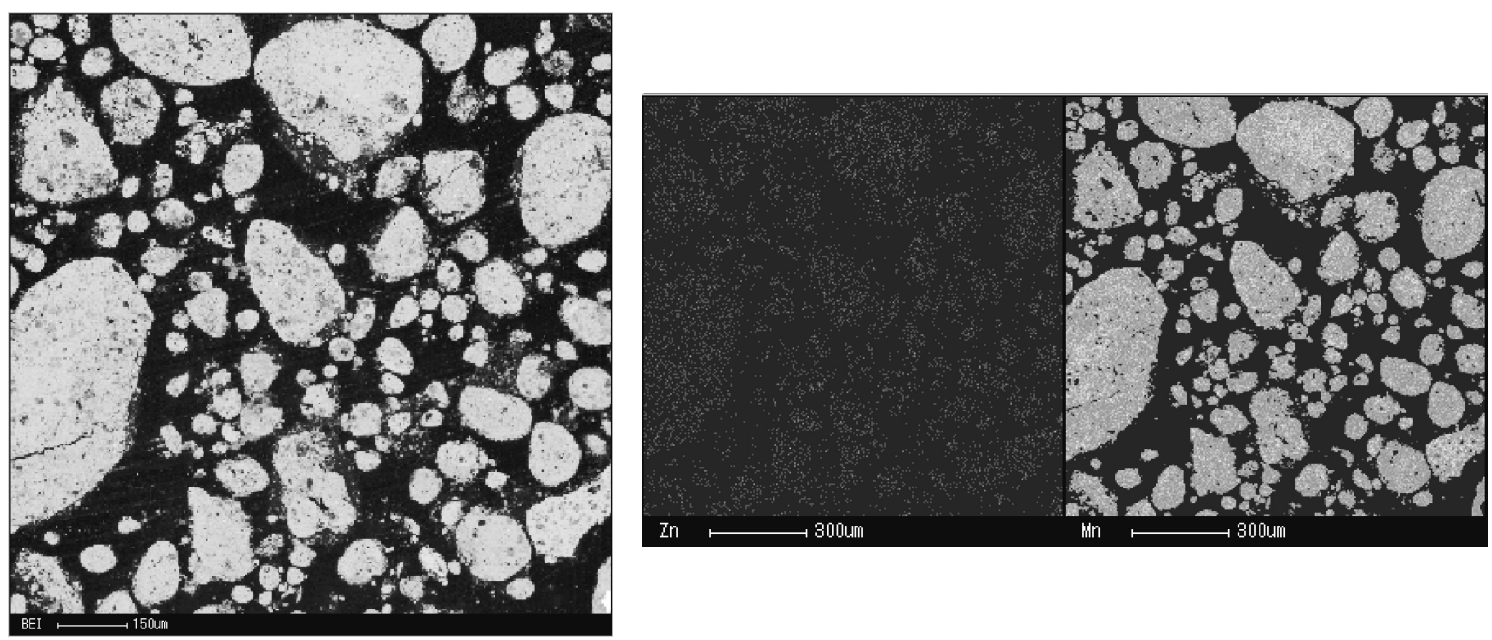

(b) The produced particles after reacting

Fig. 7 SEM-EDS results of particles before and after reacting for $20 \mathrm{~min}$ at $1173 \mathrm{~K}$.

The rate dependency on the reaction temperature was determined by first plotting the zinc removal ratio-time curves of Fig. 5 according to eq. (1), as shown in Fig. 8. Here, straight lines with high-correlation coefficient $(r>$ $0.975)$ were selected. The examination revealed that the rate data followed relatively well eq. (1). The values of $k_{\mathrm{r}}$ were thus determined from the slopes of the figure. The slopes were calculated by regression analysis. Figure 9 is Arrhenius plot of the rate constants. The slope of the straight line placed through the experimental points yield an activation energy of $173 \mathrm{~kJ} / \mathrm{mol}$. The line is represented by the following equation:

$$
k_{\mathrm{r}}=1.63 \times 10^{6} \cdot \exp \left[-\frac{20,807}{T}\right]\left(\mathrm{min}^{-1}\right)
$$

The activation energy obtained is quite high, but it is relatively lower than those obtained for the pure zinc oxide with carbon monoxide and carbon dioxide mixtures (253 $\mathrm{kJ} / \mathrm{mol})^{6)}$ and for the pure zinc oxide with solid carbon

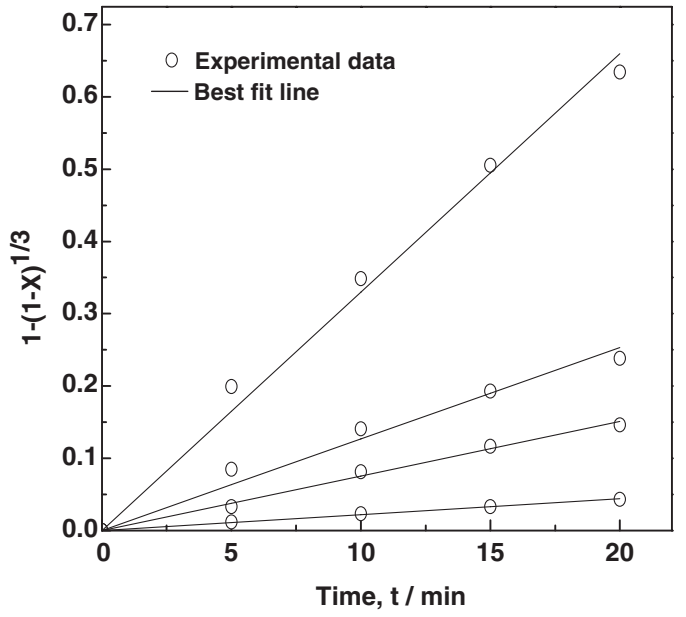

Fig. 8 Plot of the results in Fig. 5 according to eq. (1). 


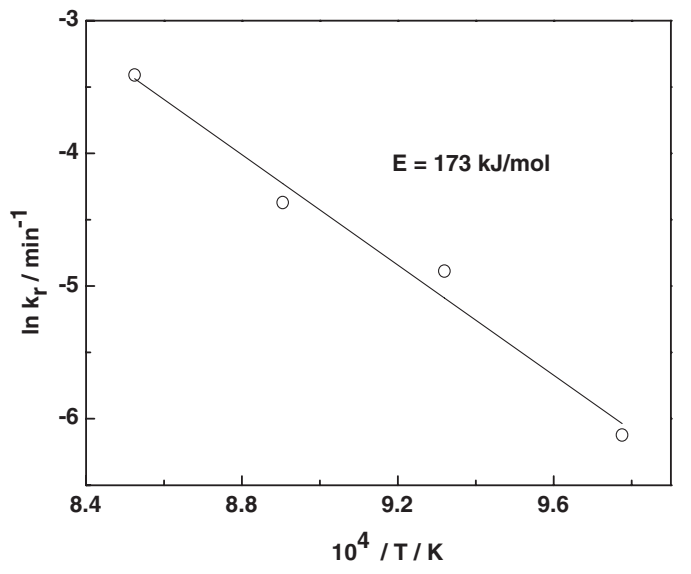

Fig. 9 Arrhenius plot of the rate constants obtained from the results of Fig. 5.

$(224 \mathrm{~kJ} / \mathrm{mol}) .{ }^{7)}$ The difference might be due to the characteristics of zinc oxide particle such as reactivity and porosity. The result indirectly indicates that the reduction-volatilization reaction of zinc oxide in the manganese dust with carbon is controlled by a surface chemical reaction. However, the effects of a solid-solid reaction like reaction (1) and a chain reaction involving reaction (2) and reaction (3) on the reduction-volatilization reaction rate of the zinc oxide in the manganese dust with carbon were not distinguished in the present research.

\section{Conclusion}

The reduction-volatilization reaction of zinc oxide contained in the manganese dust by carbon was investigated at reaction temperatures between 923 and $1323 \mathrm{~K}$ under nitrogen atmosphere using a thermogravimetric method. At a reaction temperature of $1223 \mathrm{~K}$, zinc in the manganese dust was not completely removed by carbon contained in the dust without adding carbon, but at the carbon addition amounts over 9 mass \%, it was almost completely removed in 20 min. This might be the reason that most of carbon contained in the dust is tar components, and increasing carbon addition results in an increase in the reaction surface area and provides more carbon monoxide. The reduction-volatilization reaction of zinc oxide in the manganese dust started above $973 \mathrm{~K}$ and was very fast above $1023 \mathrm{~K}$. When the temperature was higher than $1173 \mathrm{~K}$, the zinc in the dust was completely removed in $20 \mathrm{~min}$ at the carbon addition amount of 9 mass $\%$. During the reaction of zinc oxide contained in the dust with carbon, manganese and iron oxides in the dust was reduced partially. The shrinking-core model for a surface chemical reaction control was found to be useful in describing the reduction-volatilization reaction rate. The activation energy of the reaction was calculated to $173 \mathrm{~kJ} / \mathrm{mol}$.

\section{Acknowledgements}

This research was supported by the Research Project funded by the Ministry of Knowledge Economy of Korea.

\section{REFERENCES}

1) Dongbu Metal Company, Donghae-city, Kangwon-do, Korea, private communication (June 2009).

2) R. Shen, G. Zhang, M. Dellamico, P. Brown and O. Ostrovski: ISIJ Int. 45 (2005) 1248-1254.

3) R. Shen, G. Zhang, M. Dellamico, P. Brown and O. Ostrovski: ISIJ Int. 46 (2006) 8-13.

4) C. E. Guger and F. S. Manning: Met. Trans. 2 (1971) 3083-3090.

5) B. S. Kim, E. Y. Kim, H. S. Jeon, H. I. Lee and J. C. Lee: Mater. Trans. 49 (2008) 2147-2152.

6) G. Gonzalez, Z. S. Jordens and S. Escobedo: Thermochim. Acta 278 (1996) 129-134.

7) B. S. Kim, J. M. Yoo, J. T. Park and J. C. Lee: Mater. Trans. 47 (2006) 2421-2426.

8) E. R. Stobbe, B. A. De Boer and J. W. Geus: Catalysis Today 47 (1999) 161-167.

9) J. Szekely, J. W. Evans and H. Y. Sohn: Gas-solid reactions, (New York, Academic Press Inc., 1976) pp. 65-75. 